\section{Autologous non-cultured epidermal cell suspension combined with platelet rich fibrin for the treatment of stable vitiligo: A case series}

\section{Adniana Nareswari, Dendy Zulfikar, Indah Julianto, Suci Widhiati}

Dermatovenereology Department Medical Faculty of Sebelas Maret University/Dr. Moewardi General Hospital, Surakarta, Indonesia

\begin{abstract}
Non-cultured epidermal cell suspension (NCECS) is a relatively new cellular grafting technique for vitiligo. Platelet rich fibrin (PRF) is a platelet and immune concentrate gather on a single fibrin membrane which can be used in conjunction with grafts and has several advantages, such as promoting wound healing, haemostasis, and give better handling properties to graft materials. This study was conducted to determine the efficacy of NCECS combined with PRF in patients with stable vitiligo. Seven patients with stable vitiligo which not responding to topical and phototherapy for more than 12 months were included in the study. The melanocytes were harvested as an autologous melanocyte rich suspension from a donor skin. The non cultured melanocyte transplanted to recipient area that had been superficially dermabraded and smeared with PRF gel. Of all 7 patients, 1 patients showed excellent pigmentation (90-100\%), 2 had good repigmentation (60-89\%), 1 had fair repigmentation $(25-59 \%)$ and 3 patients had a poor response $(0-24 \%)$. The procedure is safe and promising surgical modality for stable vitiligo.
\end{abstract}

\section{Introduction}

Vitiligo is an acquired pigmentary disorder of the skin which is characterized by well-defined depigmented macules or patches thought to occur secondary to melanocyte dysfunction and loss. It is the most common depigmentation disorder, affecting approximately 0.5 to 2.0 percent of the population and has no predilection for gender or race. ${ }^{1}$ There are several hypotheses in the etiopathogenesis of this disease. Autoimmune, neurohumoral, cytotoxic, oxidative stress and genetic hypotheses are the most popular theory. It seems that the etiology of vitiligo is multifactorial and each of the factors plays an important role in the pathogenesis. Depigmentation may be the source of severe psychological distress, diminished quality of life, and increased risk of psychiatric morbidity. ${ }^{2}$

In vitiligo which does not respond to medical treatment, several surgical procedures includes tissue grafts and cellular graft have been reported to be effective. ${ }^{3}$ Tissue grafts such as full-thickness punch grafts, split-thickness grafts and suction blister grafts are limited to small areas while the cellular grafts included cultured autologous epithelial grafts, cultured melanocytes and non-cultured melanocytes-keratinocytes can cover larger area of vitiligo. The cellular non-cultured graft technique has the additional advantage that a laboratory equipped for cell cultures is not necessary. ${ }^{4}$

Platelet rich fibrin (PRF) is a platelet and immune concentrate gather on a single fibrin membrane, containing all the components of a blood sample which are favorable for healing and immunity. ${ }^{5}$ In this study, we used Gauthier and Benzekri ${ }^{6}$ method with a modifying technique by adding PRF to the autologous non-cultured epidermal cell suspension (NCECS) which never done in other study before to achieve better manipulation of transplanted cells.

\section{Materials and Methods}

\section{Study Design and Patients}

This interventional controlled study was conducted from December 2017 to June 2018, in dr. Moewardi General Hospital Surakarta. All the patients were screened at the preliminary visit. Seven cases of stable vitiligo were treated by autologous non-cultured epidermal cell suspension (NCECS) combined wth PRF transplantation. Inclusion criteria were the stability of vitiligo lesions for more than 1 year, aged older than 18 y.o and never received any treatment in the past one month. Exclusion criteria were the activity of vitiligo, including koebnerization or keloidal tendency, history of bleeding disorders, anticoagulant medications, pregnancy and positive for HIV and HbsAg. Clinical photographs were taken before the procedure and then at week 1,4 and 16 to compare the pigmentation change and color match. The endpoint selected was 24 weeks after the transplantation procedure.

\section{Donor site}

A punch biopsy specimen was taken from the patient's normal pigmented femoral area locally anaesthetized using intralesional lidocaine. An area of epidermis containing minimal underlying dermis was
Correspondence: Adniana Nareswari, Dermatovenereology Department Medical Faculty of Sebelas Maret University/Dr. Moewardi General Hospital, Surakart. Jl. Kolonel Sutarto No.132, Jebres, Jebres, Surakarta, Central Java 57126.

Phone: 082134637293.

E-mail: adniananareswari@gmail.com

Key words: Stable vitiligo, Non-cultured epidermal cell suspension, non-cultured melanocyte.

Contributions: AN wrote the manuscript with input from all of the other authors. AN and DZ provided data for Table 1, performed the experiments and analysed the data. IJ and SW verified the analytical method and helped supervise the study/project. All authors reviewed the final manuscript.

Conflict of interest: The authors declare no potential conflict of interest.

Funding: none.

Received for publication: 1 February 2019. Accepted for publication: 1 February 2019.

This work is licensed under a Creative Commons Attribution-NonCommercial 4.0 International License (CC BY-NC 4.0).

(C) Copyright A. Nareswari et al., 2019

Licensee PAGEPress, Italy

Dermatology Reports 2019; 11(s1):8016

doi:10.4081/dr.2019.8016

punched. It was approximately one tenth of the recipient area. The donor site was covered by topical antibiotic and secured by gauze and adhesive tape.

\section{Non-cultured autologous} melanocyte-keratinocyte suspension

\section{Sample preparation}

The skin tissue was immediately transferred to a transport medium to the laboratory and washed three times using phosphate buffered saline (PBS) which containing antibiotics and antimikotics (penicillin, streptomycin and amphotericin B). The tissue was cut into tiny pieces and cleansed slowly from the remnants so the epidermis was separated from the dermis and keratin tissues. The epidermis then transferred to the sterile Falcon and incubated with $2.5 \mathrm{ml}$ of $0.25 \%$ trypsin $-0.05 \%$ ethylene diamine tetraacetic acid (EDTA) at $37^{\circ} \mathrm{C}$ for $15-30$ minutes to prepare a single cell suspension. After 15 minutes, $2.5 \mathrm{ml}$ of trypsin inhibitor was added and left it for 10 minutes. Then filtration was done with a 70 um cell strainer. Next the cell suspension was centrifuged for 5 minutes at $2000 \mathrm{rpm}$. The supernatant 
was discarded to obtain the cell pellet. It was then resuspended in $2 \mathrm{ml}$ of Dulbecco's modified eagle medium (DMEM) as nutrient medium before planted in recipient area. The number of cells in the suspension were counted manually by the haemocytometer. Survival of cell suspension was examined with trypan blue dye exclusion method (Figure 1).

\section{Recipient site}

The recipient site was surgically cleansed and was anesthetized using topical EMLA (lidocaine 2.5\%, prilocaine 2.5\%). The recipient area was abraded manually until tiny pinpoint bleeding spots were seen. Using an $18 \mathrm{~g}$ needle attached to a tuberculin syringe or a pipette, few small drops of suspension were placed over the denuded surface, flattened to cover all the dermabraded area, then covered with fibrin matrix and dressed with first sofratulle, then cell suspension again followed by the second dressing of sofratulle, finally covered with topical antioxidant gel and sterile cotton pad. After the procedure, patients were instructed to lie at least 2 hours to allow successful attachments of cells to the transplant area and advised to keep the dressing dry and minimize local manipulation. An oral broad spectrum antibiotic was given for 7 days to avoid infection of the donor and grafted areas. All dressings were removed after 7 days.

\section{Results}

\section{Demographic and disease characteristics}

Demographic characteristics are shown in Table 1 . The patients were 2 males and 5 females with age ranged from 18 to 78 years (mean 33.4). Three patients had segmental vitiligo, two had acrofacial localized vitiligo, one focal vitiligo vulgaris, and one focal vitiligo. The stability duration of the vitiligo ranged from 13 to 180 months (mean 49.1) (Table 1).

\section{Repigmentation}

The patients were planned to be followed up regularly for a period of 6 months. We used Photoshop-based image analysis using the color information contained in each individual pixel and allowed the separation of colours at the pixel resolution level. And the degree of repigmentation was evaluated qualitatively on the basis of visual analogue system score for the extent of pigmentation and color match. Most of our patients started developing repigmentation within 4-24 weeks, it is characterized by the appearance of normal pigmented macules and/or patches (Figure 2).

\section{Laboratory analysis}

Average total cell count using Neubauer chamber was $2-30 \times 10^{5} / \mathrm{ml}$. Small cells were identified as keratinocytes and melanocytes, and large pale cells were identified as fibroblasts. Cell viability was assessed with trypan blue staining, and the percentage of viability was $97 \%$.

\section{Discussion}

Vitiligo is an acquired, idiopathic depigmentation disorder characterized by well defined white patches of variable shape and dimensions. ${ }^{7}$ Several therapeutic options, both medical and surgical are available for repigmentation of vitiligo, although none provides truly satisfactory results. An ideal surgical modality should not only provide a good colour and texture match of recipient area with the surrounding normal skin, but also induce minimal or no complications at donor site, especially no permanent scarring. Noncultured epidermal cell suspension is a one-time day care procedure for vitiligo allowing treatment of recipient area manifold larger than donor site area. ${ }^{8}$ Since its introduction by Gauthier and Surleve Bazeille ${ }^{4}$ in 1992 the technique of NCECS has undergone several modifications. Studies by Van Geel et al. ${ }^{9}$ and Mulekar et al. ${ }^{10}$ have established NCECS as a strategic treatment modality for stable vitiligo at multiple centres. We share our experience of this technique in stable vitili-
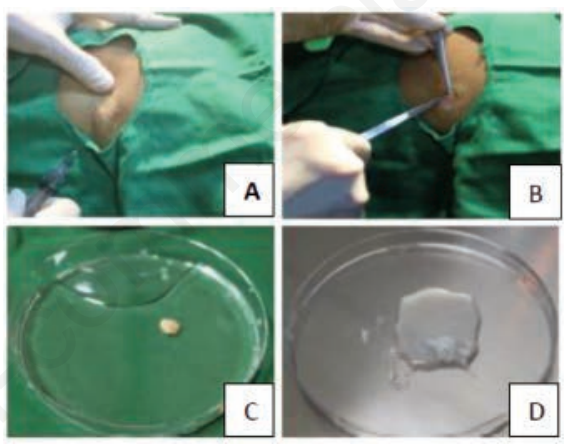

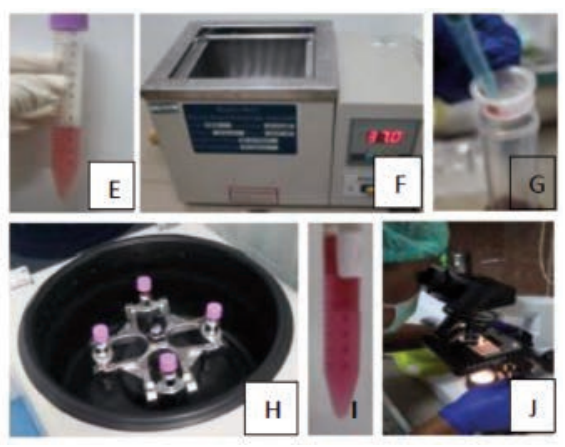

Figure 1. Preparation of autologous NCECS. A-B. Donor area were anaesthetized and punched. C-D. Punched skin was cut into tiny pieces. E-F The epidermis tripsinized then incubated at $37^{\circ} \mathrm{C}$. G-H. Filtered and centrifuged for 5 minutes at $2000 \mathrm{rpm}$. I. Pellet cell resuspended with $2 \mathrm{ml}$ DMEM J. Manually counted by haemocytometer

Table 1. Demographic distribution of patients and the percentage change of the depigmented areas (from baseline) in the patches treated with melanocytes transplantation.

\begin{tabular}{lcccccc}
\hline Patient & Sex & Age (years) & Area treated & Type & Duration of stability (Months) & Repigmentation after 6 months (\%) \\
1 & M & 42 & Left hand & Acrofacial & 36 & 10 \\
2 & F & 78 & Hand & Acrofacial & 18 & 25 \\
\hline 3 & F & 22 & Back & Focal & 60 & 5 \\
4 & F & 25 & Right forehead & Segmental & 180 & 94 \\
\hline 5 & F & 31 & Right hand & Vulgaris & 13 & 85 \\
6 & F & 18 & Left shoulder & Segmental & 24 & 70 \\
\hline 7 & M & 18 & Face & Segmental & 13 & 15 \\
\hline
\end{tabular}




\section{BEFORE}
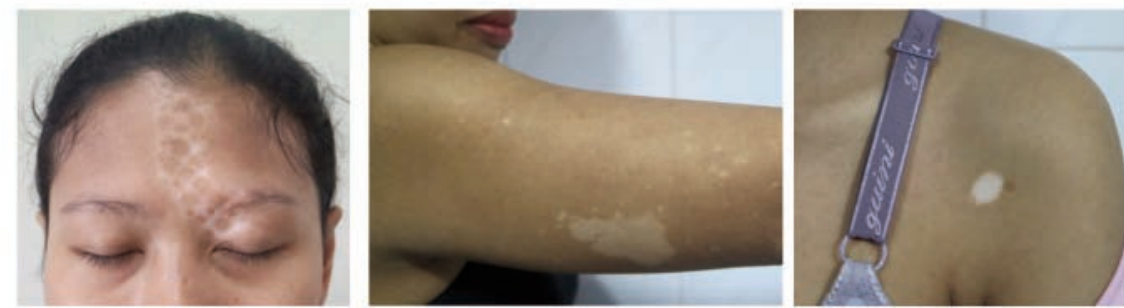

AFTER
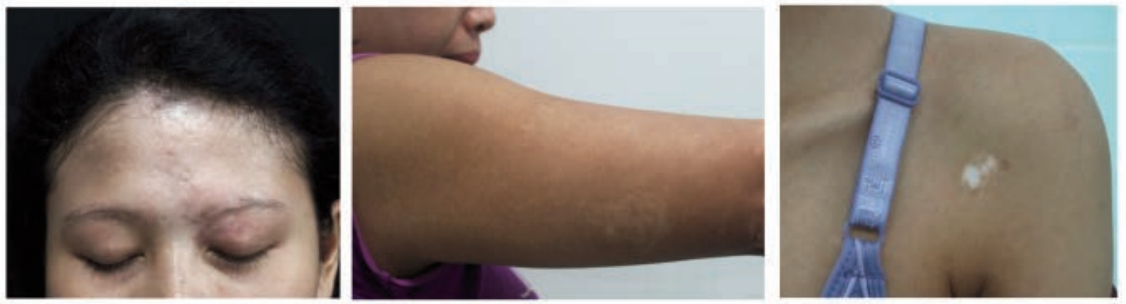

Figure 2. Repigmentation in the week 24 of follow up, it is characterized by the appearance of normal pigemented macules and patches. (A) Before; (B) after.

go. In our present study, we observes and continue follow up the patients until at least 24 weeks. In a study by Leelavathy et al. among NCECS group, majority of patients showed poor pigmentation (53.33\%) followed by $46.67 \%$ with good pigmentation at 6 weeks. At 12 weeks, excellent repigmentation was observed in $6.67 \%$ of patients and $30 \%$ patients showed very good repigmentation. ${ }^{11}$ In the study by Van Geel et al. ${ }^{9} 13.55 \%$ patients showed $70 \%$ repigmentation at 12 weeks post op. At 24 weeks, excellent repigmentation $(>90 \%)$ was observed in $66.67 \%$, very good response (with 75\%-90\% repigmentation) in $16.67 \%$ and good response (with $50 \%$ $75 \%$ repigmentation) in $13.33 \%$ of patients.

PRF consists of a fibrin matrix polymerized in a tetra molecular structure, with consolidation of platelets, leucocytes, cytokines, and circulating stem cells. ${ }^{12,13}$ Clinical studies showed that its biomaterial would be a great matrix for the development of a coherent healing, without any inflammatory excess. PRF in the form of a platelet gel can be used in conjunction with grafts, which has several advantages, such as promoting wound healing, haemostasis, and give better handling properties or scaffolding to graft materials. ${ }^{14}$

\section{Conclusions}

This NCECS transplantation combined with PRF is a promising technique in vitiligo surgical intervention. The procedure is simple without complicated laboratory facility.

\section{References}

1. Medicina D. Seminar Vitiligo. 2015; 6736(14):1-11.

2. Alikhan A, Felsten LM, Daly M, Petronic-Rosic V. Vitiligo: A comprehensive overview: Part I. Introduction, epidemiology, quality of life, diagnosis, differential diagnosis, associations, histopathology, etiology, and work-up. J Am Acad Dermatol. 2011; 65(3):473491.

3. Naeyaert NVGKOJ. Surgical Techniques for Vitiligo: A Review.
$2001 ; 162-166$

4. Gauthier Y, Surleve-Bazeille JE. Autologous grafting with noncultured melanocytes: a simplified method for treatment of depigmented lesions. J Am Acad Dermatol. 1992;26 (2 Pt 1):191-4

5 Mosesson MW, Siebenlist KR, Meh DA. The structure and biological features of fibrinogen and fibrin. Ann N Y Acad Sci. 2001; 936:11-30.

6. Gauthier Y, Benzekri L. Non-cultured epidermal suspension in vitiligo: From laboratory to clinic. Indian $\mathrm{J}$ Dermatology, Venereol Leprol. 2012; 78(1): 59

7. Glassman SJ. Vitiligo, reactive oxygen species and T-cells. Clin Sci (Lond). 2011;120(3):99-120

8. Paul M. Autologous Non-cultured Basal Cell-Enriched Epidermal Cell Suspension Transplantation in Vitiligo: Indian Experience. J Cutan Aesthet Surg. 2011; 4(1):23-8

9. Van Geel N, Ongenae K, De Mil M, Haeghen YV, Vervaet C, Naeyaert JM. Double-blind placebo-controlled study of autologous transplanted epidermal cell suspensions for repigmenting vitiligo. Arch Dermatol. 2004;140(10): 1203-8

10. Mulekar SV. Melanocyte-keratinocyte cell transplantation for stable vitiligo. Int J Dermatol 2003;42:132-6.

11. Leelavathy B, Akshi Bansal, Shilpa K. To Evaluate the Efficacy of NonCultured Epidermal Cell Suspension in Cases of Stable Vitiligo. Clin Surg. 2017; 2: 1527.

12. Choukroun J, Diss A, Simonpieri A, Girard MO, Schoeffler C, Dohan SL, et al. Platelet-rich fibrin (PRF):A secondgeneration platelet concentrate, Part IV: Clinical effects on tissue healing. Oral Surg Oral Med Oral Pathol Oral Radiol Endod. 2006;101: E56-60.

13. Choukroun J, Diss A, Simonpieri A, Girard MO, Schoeffler C, Dohan SL, et al. Platelet-rich fibrin (PRF): A secondgeneration platelet concentrate. Part V: Histologic evaluations of PRF effects on bone allograft maturation in sinus lift. Oral Surg Oral Med Oral Pathol Oral Radiol Endod. 2006;101:299-303.

14. Sunitha R, Munirathnam N. Plateletrich fibrin: Evolution of a second generation platelet concentrate. Indian J Dent Res. 2008;19:42-6. 